\title{
Comparative associations between anticholinergic burden and emergency department visits for anticholinergic adverse events in older Korean adults: a
} nested case-control study using national claims data for validation of a novel country-specific scale

Sunghee Hwang ${ }^{1 \dagger}$, Jee Eun Chung ${ }^{1 \dagger}$, Kwanghee Jun², Young-Mi Ah³ ${ }^{3}$ Kwang-II Kim ${ }^{4}$ and Ju-Yeun Lee $2^{2^{*}}$ (I)

\begin{abstract}
s
Background: Considering the limited generalizability of previous anticholinergic burden scales, the Korean Anticholinergic Burden Scale (KABS) as a scale specific to the Korean population was developed. We aimed to validate the KABS by detecting the associations between high anticholinergic burden, measured with the KABS, and emergency department (ED) visits compared to the pre-existing validated scales in older Korean adults.

Methods: A nested case-control study was conducted using national claims data. The cases included the first anticholinergic ED visits between July 1 and December 31, 2016. Anticholinergic ED visits were defined as ED visits with a primary diagnosis of constipation, delirium, dizziness, fall, fracture, or urinary retention.

Propensity score-matched controls were identified. Average daily AB scores during 30 days before the index date were measured. Multivariate logistic regression analyses were performed.

Results: In total, 461,034 were included. The highest proportion of those with high AB was identified with KABS (5.0\%). Compared with those who had a KABS score of 0, older adults with a score $\geq 3$ were at higher risk for overall anticholinergic ED visits (aOR, 1.62, 95\% Cl, 1.53-1.72), as well as visits for falls/fractures (aOR: 1.54, 95\% Cl: 1.40-1.69), dizziness (aOR: 1.44, 95\% Cl: 1.30-1.59), delirium (aOR: 2.96, 95\% Cl: 2.28-3.83), constipation (aOR: 1.84, 95\% Cl: 1.682.02), and urinary retention (aOR: $2.13,95 \% \mathrm{Cl}: 1.79-2.55$ ). High AB by KABS showed a stronger association with overall anticholinergic ED visits and visits due to delirium and urinary retention than those by other scales.

(Continued on next page)
\end{abstract}

\footnotetext{
* Correspondence: jypharm@snu.ac.kr

${ }^{\dagger}$ Sunghee Hwang and Jee Eun Chung contributed equally to this work.

${ }^{2}$ College of Pharmacy and Research Institute of Pharmaceutical Sciences,

Seoul National University, Seoul, Republic of Korea

Full list of author information is available at the end of the article
}

(c) The Author(s). 2021 Open Access This article is licensed under a Creative Commons Attribution 4.0 International License, which permits use, sharing, adaptation, distribution and reproduction in any medium or format, as long as you give appropriate credit to the original author(s) and the source, provide a link to the Creative Commons licence, and indicate if changes were made. The images or other third party material in this article are included in the article's Creative Commons licence, unless indicated otherwise in a credit line to the material. If material is not included in the article's Creative Commons licence and your intended use is not permitted by statutory regulation or exceeds the permitted use, you will need to obtain permission directly from the copyright holder. To view a copy of this licence, visit http://creativecommons.org/licenses/by/4.0/ The Creative Commons Public Domain Dedication waiver (http://creativecommons.org/publicdomain/zero/1.0/) applies to the data made available in this article, unless otherwise stated in a credit line to the data. 
(Continued from previous page)

Conclusions: In conclusion, KABS is superior to pre-existing scales in identifying patients with high AB and predicting high AB-related ED visits in older Korean adults.

Keywords: Anticholinergic syndromes, Cholinergic antagonists, Emergency medical services, Geriatrics

\section{Background}

Anticholinergic drugs are often prescribed for the treatment of various diseases or for the relief of various symptoms, but they are often characterized as inappropriate for older adults [1]. Anticholinergic burden is defined as the cumulative effects of taking multiple drugs with anticholinergic properties [2]. A high anticholinergic burden can cause a variety of negative consequences, including cognitive impairment, confusion, delirium, falls, dry mouth, constipation and urinary retention [2].

Anticholinergic burden has become a prominent indicator used to evaluate the quality of prescribing practices in geriatric pharmacotherapy [3]. This assessment is used to recognize the risk of drug-related complications and to reduce unnecessary anticholinergic prescriptions in medication reviews for polypharmacy in older adults. A study conducted in the United Kingdom by Tay et al. [4] found that simply measuring the $A B$ then reporting it to the physician could reduce anticholinergic prescriptions. A study by Ailabouni et al. [5] showed that anticholinergics or sedatives could be deprescribed after a pharmacist performed a medication review.

Several assessment scales, such as the Anticholinergic Risk Scale (ARS) [6], the Anticholinergic Cognitive Burden Scale (ACB) [7], and the Anticholinergic Drug Scale (ADS) [8] have been developed to evaluate anticholinergic burden and predict potential anticholinergic adverse effects $[9,10]$. However, these scales were difficult to apply to Korean population due to their limited generalizability and the inconsistencies of listed medications and their anticholinergic potency scores. The limited generalizability was related to the difference in prescribing practices as well as the availability of the medications between countries. In addition, these differences could have occurred with the change of times after development of the scale [11]. For these reasons, there is no consensus on which scoring system is most useful in clinical settings to date [12]. To overcome these limitations, we developed the Korean Anticholinergic Burden Scale (KABS) as a scale specific to the Korean population, through a modified Delphi process using the previously developed scales but with the addition of Korean-specific anticholinergic medications [13]. This scale re-evaluated the medications with mismatched anticholinergic scores in the previous scales and included the anticholinergic medications commonly used in South Korea that were not rated in existing scale [13]. Previous studies reported that identification of populations at risk for adverse anticholinergic effects and the predictive validity for negative clinical outcomes may depend on the scales applied [10, 14-16]. Therefore, before adopting the KABS in clinical practice, it is essential to confirm its practicality by evaluating the association between KABS and negative clinical outcomes.

The preponderance of previous studies focused on the chronic, central nervous system adverse effects, such as dementia or cognitive impairment, or falls as the marker of negative outcomes secondary to high anticholinergic burden. However, from the perspectives of patients and healthcare systems alike, it is important to include other severe or acute adverse effects, including urinary retention, constipation, dizziness, delirium, and a fall or fracture, leading to ED visits as they increase the economic and cost burden [17].

Based on these previous findings, we aimed to validate the novel KABS by detecting the associations between high anticholinergic burden, measured with the KABS, and ED visits related to anticholinergic adverse effects (constipation, dizziness, delirium, falls, fractures, or urinary retention) compared to the pre-existing validated scales in Korean older adults.

\section{Methods}

\section{Study design and population}

We conducted a nested case-control study using an older adult patient sample (APS) dataset provided by the Health Insurance Review and Assessment Service (HIRA), the HIRA-APS 2016. Under the Korean national health insurance system, which includes $98 \%$ of the Korean population, HIRA originally receives claims data to evaluate claims for medical services that healthcare providers deliver to patients prior to reimbursement. Using stratified random sampling method, HIRA provided the HIRAAPS, which contained approximately one million individuals $(20 \%)$ randomly selected from all patients aged 65 years or over in 2016 [18] . This dataset exhibits 95\% concordance with the actual population, demonstrating a high level of representativeness. The HIRA claims data include basic socio-demographic information, specific information on health service provided including procedures, prescription data and diagnostic information.

The study design is depicted in Fig. 1. The cases consisted of older adults who visited an ED due to anticholinergic adverse effects, an anticholinergic ED visits, from July 1 to December 31, 2016. Anticholinergic 


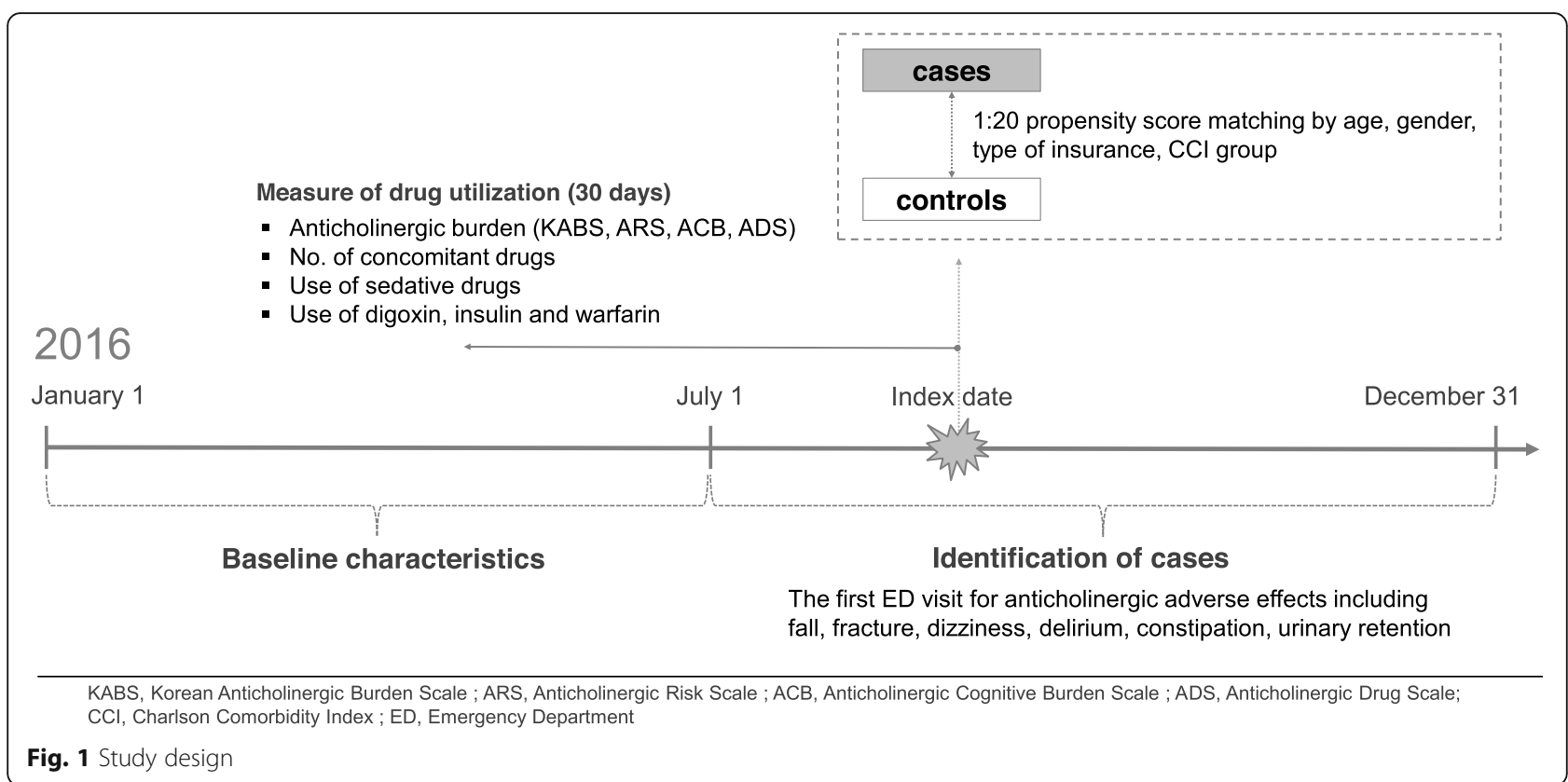

adverse effects were identified using primary diagnostic codes related to constipation, dizziness, delirium, falls, fractures, or urinary retention (Additional file 1) and the first anticholinergic ED visit was set as the index date. Patients who had anticholinergic ED visits prior to the index date were excluded. The controls were matched to cases using a propensity score (1:20) according to age, sex, insurance type, and Charlson Comorbidity Index (CCI) score $(0,1-2, \geq 3)$ among those who did not visit an ED during 2016. Propensity score matching was performed using a greedy algorithm with a caliper width equal to 0.2 standard deviations of the logit of the propensity score without replacement. We assigned the index date of control as the date at which the event occurred for the matched cases.

This study obtained an ethical approval from the Institutional Review Board of Hanyang University (No. HYI17-007-1). Informed consent was waived because we used encrypted claims data.

\section{Measurement of anticholinergic medication exposure}

A patient's anticholinergic burden was calculated as the average daily anticholinergic burden score for all prescribed drugs during the 30 days before the index date using the KABS [13], ARS [6], ACB [7] and ADS [8]. All four scales employ a 4-point scale from 0 , of limited or none, to 3 , of very strong, to rank the anticholinergic burden. The comparable list of anticholinergic drugs included in each of the four scales is presented in Additional file 2. Topical agents were excluded. We converted the dose of each medication to the defined daily dose (DDD) assigned by the WHO [19]. The average daily anticholinergic burden score was calculated based on the pre-rated anticholinergic potency, dosage and treatment duration as described in the previous study [20]. For this analysis, average daily scores were rounded to the nearest integer, and score of 3 or greater was defined as a high anticholinergic burden.

\section{Covariates}

Baseline characteristics were collected from January to June 2016. Sociodemographic variables, including age, sex, and type of insurance were collected. Comorbid medical conditions, CCI scores, and concomitant chronic medications prescribed for more than 18 days during a month were identified as covariates. Among the concomitant chronic medications, we identified the number of medications, the use of sedatives, insulins, warfarin, and digoxin. The diagnostic codes used to identify comorbidities are presented in Additional file 1. To adjust for the increased risk of adverse effects, such as falls or fractures, due to the use of sedatives not on the list of anticholinergic burden scale [21], exposure to drugs listed on the sedative load model [22] was also evaluated. All these covariates were adjusted for in the multivariate logistic regression.

\section{Statistical analysis}

Descriptive statistics were used to report the baseline characteristics and medication exposures. To compare the variables between the cases and control groups, we used t-test and chi-square statistics for numerical data and categorical data, respectively. A multivariate logistic regression analysis was performed to investigate the associations between anticholinergic burden and ED visits for all causes as well as for each specific cause, and the adjusted odds ratio (aOR) and 95\% confidence interval (CI) were presented. Statistical significance was defined 
as $p<0.05$. All statistical analyses were carried out with SAS version 9.4 (SAS Institute Inc., Cary, NC, USA).

\section{Results}

Among a total of 1,327,455 older adults in the HIRA-APS 2016 dataset, 461,034 were included in this study. Table 1 presents the baseline characteristics and drug utilization data for the study population. The population had a mean age of $76.1 \pm 7.1$ years, and $39.1 \%$ were male. The mean CCI score was $2.11 \pm 1.93$, and diabetes mellitus $(29.7 \%)$ was the most common comorbidity. There were 202,939 older adults (44.1\%) taking 5 or more drugs. Forty-nine percent of the population was exposed to sedatives and the use of the high-risk medications, digoxin, insulins and warfarin were $1.4,1.3$, and $0.9 \%$, respectively. Although the frequency of patients within groups divided by CCI score were similar between case and control, the mean CCI score was higher in case than control ( $2.25 \pm 2.16$ vs. $2.10 \pm 1.92, p<0.001)$. Pre-defined co-morbid conditions, polypharmacy, excessive polypharmacy, use of sedative drugs, digoxin, insulin and warfarin were significantly more prevalent among cases than controls (Table 1). These variables were included as covariates for adjustment in the multivariate logistic regression.

Table 1 Baseline characteristics of the study population $(N=461,034)$

\begin{tabular}{|c|c|c|c|c|c|c|c|}
\hline \multirow[t]{2}{*}{ Characteristics } & \multicolumn{2}{|c|}{$\begin{array}{l}\text { Total } \\
(N=461,034)\end{array}$} & \multicolumn{2}{|c|}{$\begin{array}{l}\text { Case } \\
(N=21,954)\end{array}$} & \multicolumn{2}{|c|}{$\begin{array}{l}\text { Control } \\
(N=439,080)\end{array}$} & \multirow[t]{2}{*}{$P$ valu } \\
\hline & $\mathbf{N}$ & $(\%)$ & $\mathbf{N}$ & $(\%)$ & $\mathbf{N}$ & $(\%)$ & \\
\hline Age, mean $[S D]$ & 76.1 & {$[7.1]$} & 76.2 & {$[7.1]$} & 76.1 & {$[7.1]$} & 0.8844 \\
\hline $65-74$ & 204,246 & $(44.3)$ & 9726 & $(44.3)$ & 194,520 & $(44.3)$ & 0.9743 \\
\hline $75-84$ & 194,220 & $(42.1)$ & 9238 & $(42.1)$ & 184,982 & $(42.1)$ & 0.9743 \\
\hline$\geq 85$ & 62,568 & (13.6) & 2990 & (13.6) & 59,578 & (13.6) & 0.9743 \\
\hline Gender, male & 180,351 & $(39.1)$ & 8627 & (39.3) & 171,724 & $(39.1)$ & 0.5819 \\
\hline CCl score, mean [SD] & 2.11 & {$[1.93]$} & 2.25 & {$[2.16]$} & 2.10 & [1.92] & $<.0001$ \\
\hline 0 & 97,658 & $(21.2)$ & 4658 & $(21.2)$ & 93,000 & $(21.2)$ & 0.9917 \\
\hline $1-2$ & 198,912 & $(43.1)$ & 9468 & $(43.1)$ & 189,444 & $(43.2)$ & 0.9917 \\
\hline$\geq 3$ & 164,464 & $(35.7)$ & 7828 & $(35.7)$ & 156,636 & $(35.7)$ & 0.9917 \\
\hline \multicolumn{8}{|l|}{ Health insurance type } \\
\hline Health insurance & 403,869 & $(87.6)$ & 19,228 & (87.6) & 384,641 & (87.6) & 0.9355 \\
\hline Medical aid & 57,165 & $(12.4)$ & 2726 & (12.4) & 54,439 & (12.4) & 0.9355 \\
\hline \multicolumn{8}{|l|}{ Co-morbid condition } \\
\hline Diabetes Mellitus & 136,783 & $(29.7)$ & 6702 & $(30.5)$ & 130,081 & (29.6) & 0.0043 \\
\hline COPD & 73,613 & $(16.0)$ & 4126 & (18.8) & 69,487 & $(15.8)$ & $<.0001$ \\
\hline Cerebrovascular disease & 64,855 & $(14.1)$ & 3732 & $(17.0)$ & 61,123 & (13.9) & $<.0001$ \\
\hline Coronary artery disease & 59,108 & $(12.8)$ & 3319 & $(15.1)$ & 55,789 & $(12.7)$ & $<.0001$ \\
\hline Liver failure & 37,934 & $(8.2)$ & 2215 & $(10.1)$ & 35,719 & $(8.1)$ & $<.0001$ \\
\hline Congestive heart failure & 30,984 & $(6.7)$ & 1813 & $(8.3)$ & 29,171 & (6.6) & $<.0001$ \\
\hline Cancer & 28,152 & $(6.1)$ & 1640 & $(7.5)$ & 26,512 & $(6.0)$ & $<.0001$ \\
\hline Renal failure & 10,927 & $(2.4)$ & 778 & (3.5) & 10,149 & $(2.3)$ & $<.0001$ \\
\hline Parkinson's disease & 10,347 & $(2.2)$ & 749 & $(3.4)$ & 9598 & $(2.2)$ & $<.0001$ \\
\hline \multicolumn{8}{|l|}{ Medication Use } \\
\hline No. of concomitant drugs, mean [SD] & 4.4 & {$[3.9]$} & 5.2 & {$[4.4]$} & 4.4 & {$[3.9]$} & $<.0001$ \\
\hline$<5$ & 258,095 & $(56.0)$ & 10,829 & $(49.3)$ & 247,266 & $(56.3)$ & $<.0001$ \\
\hline Polypharmacy (5-9) & 153,316 & $(33.3)$ & 7580 & (34.5) & 145,736 & $(33.2)$ & $<.0001$ \\
\hline Excessive polypharmacy $(\geq 10)$ & 49,623 & $(10.8)$ & 3545 & $(16.2)$ & 46,078 & $(10.5)$ & $<.0001$ \\
\hline Use of sedative drugs & 225,843 & $(49.0)$ & 13,797 & $(62.9)$ & 212,046 & $(48.3)$ & $<.0001$ \\
\hline Use of digoxin & 6610 & $(1.4)$ & 406 & $(1.9)$ & 6204 & (1.4) & $<.0001$ \\
\hline Use of insulin & 6077 & (1.3) & 517 & $(2.4)$ & 5560 & (1.3) & $<.0001$ \\
\hline Use of warfarin & 4278 & $(0.9)$ & 300 & $(1.4)$ & 3978 & $(0.9)$ & $<.0001$ \\
\hline
\end{tabular}


Table 2 Average daily anticholinergic burden score identified according to each four scales in the study population ( $N=461,034)$

\begin{tabular}{|c|c|c|c|c|c|c|c|c|c|c|}
\hline \multirow[t]{2}{*}{ Scale } & \multicolumn{2}{|c|}{ Any exposure } & \multicolumn{2}{|l|}{ Score 0} & \multicolumn{2}{|l|}{ Score 1} & \multicolumn{2}{|l|}{ Score 2} & \multicolumn{2}{|c|}{ Score $\geq 3$} \\
\hline & $\mathrm{N}$ & (\%) & $\mathrm{N}$ & $(\%)$ & $\mathrm{N}$ & (\%) & $\mathrm{N}$ & $(\%)$ & $\mathrm{N}$ & (\%) \\
\hline KABS & 249,523 & (54.1) & 324,457 & (70.4) & 86,278 & (18.7) & 27,436 & (6.0) & 22,863 & (5.0) \\
\hline ARS & 173,533 & (37.6) & 394,441 & (85.6) & 54,499 & (11.8) & 9143 & (2.0) & 2951 & (0.6) \\
\hline ACB & 267,386 & $(58.0)$ & 295,633 & $(64.1)$ & 112,597 & $(24.4)$ & 30,704 & (6.7) & 22,100 & (4.8) \\
\hline ADS & 252,078 & $(54.7)$ & 322,466 & $(69.9)$ & 90,167 & (19.6) & 30,784 & (6.7) & 17,617 & (3.8) \\
\hline
\end{tabular}

$A B$ anticholinergic burden, KABS Korean Anticholinergic Burden Scale, ARS Anticholinergic Risk Scale, ACB Anticholinergic Cognitive Burden scale, $A D S$ Anticholinergic Drug Scale

The average daily anticholinergic burden scores determined by the four different scales are delineated in Table 2 . The highest exposure was identified using the ACB (58.0\%), and the lowest exposure was identified using the ARS (37.6\%). The proportion of patients who had a high anticholinergic burden (score $\geq 3$ ) ascertained by the KABS, $\mathrm{ACB}, \mathrm{ADS}$, and ARS was 5.0, 4.8, 3.8, and $0.6 \%$, respectively.

As shown in Table 3, after adjusting for covariates, all 4 scales used for assessing anticholinergic burden showed clear dose-response relationships, with increased odds for ED visits due to anticholinergic adverse effects.
Anticholinergic burden measured with the KABS and ADS showed dose-dependent increases in the odds of visiting the ED due to each individual anticholinergic adverse effect. Associations with all individual anticholinergic ED visits, except dizziness, were lowest when measured with the ACB. Older adults with a KABS score $\geq 3$ were at higher risk for overall anticholinergic ED visits (aOR, 1.65; 95\% CI, 1.56-1.75) as well as ED visit for falls or fractures (aOR: 1.53, 95\% CI: 1.39-1.69), dizziness (aOR: 1.49, 95\% CI: 1.34-2.65), delirium (aOR: 2.85, 95\% CI: 2.20-3.69), constipation (aOR: 1.85, 95\% CI: 1.69-2.03), and urinary

Table 3 Association between anticholinergic burden measured by each scales and ED visits for anticholinergic adverse effects in older Korean adults $(N=461,034)$

\begin{tabular}{|c|c|c|c|c|c|c|c|c|c|c|c|c|}
\hline \multirow[t]{2}{*}{$\begin{array}{l}\text { Scale and } \\
\text { Score }\end{array}$} & \multicolumn{2}{|c|}{$\begin{array}{l}\text { Anticholinergic ED visits } \\
(N=21,954)\end{array}$} & \multicolumn{2}{|c|}{$\begin{array}{l}\text { Fall or fracture } \\
(N=8124)\end{array}$} & \multicolumn{2}{|c|}{$\begin{array}{l}\text { Dizziness } \\
(N=7026)\end{array}$} & \multicolumn{2}{|c|}{$\begin{array}{l}\text { Delirium } \\
(N=719)\end{array}$} & \multicolumn{2}{|c|}{$\begin{array}{l}\text { Constipation } \\
(N=7141)\end{array}$} & \multicolumn{2}{|c|}{$\begin{array}{l}\text { Urinary retention } \\
(N=1878)\end{array}$} \\
\hline & $\mathrm{aOR}^{\mathrm{a}}$ & $(95 \% \mathrm{Cl})$ & $\mathrm{aOR}^{\mathrm{a}}$ & $(95 \% \mathrm{Cl})$ & $\mathrm{aOR}^{\mathrm{a}}$ & $(95 \% \mathrm{Cl})$ & $\mathrm{aOR}^{\mathrm{a}}$ & $(95 \% \mathrm{Cl})$ & $\mathrm{aOR}^{\mathrm{a}}$ & $(95 \% \mathrm{Cl})$ & $\mathrm{aOR}^{\mathrm{a}}$ & $(95 \% \mathrm{Cl})$ \\
\hline \multicolumn{13}{|l|}{ KABS } \\
\hline 0 (reference) & 1.00 & & 1.00 & & 1.00 & & 1.00 & & 1.00 & & 1.00 & \\
\hline 1 & 1.30 & $(1.26-1.35)$ & 1.24 & $(1.17-1.31)$ & 1.23 & $(1.15-1.30)$ & 1.36 & $(1.12-1.66)$ & 1.38 & $(1.30-1.47)$ & 1.50 & $(1.34-1.69)$ \\
\hline 2 & 1.46 & $(1.38-1.54)$ & 1.37 & $(1.25-1.49)$ & 1.29 & $(1.17-1.41)$ & 1.91 & $(1.46-2.50)$ & 1.68 & $(1.54-1.84)$ & 1.68 & $(1.41-2.00)$ \\
\hline$\geq 3$ & 1.62 & $(1.53-1.72)$ & 1.54 & $(1.40-1.69)$ & 1.44 & $(1.30-1.59)$ & 2.96 & $(2.28-3.83)$ & 1.84 & $(1.68-2.02)$ & 2.13 & $(1.79-2.55)$ \\
\hline \multicolumn{13}{|l|}{ ARS } \\
\hline 0 (reference) & 1.00 & & 1.00 & & 1.00 & & 1.00 & & 1.00 & & 1.00 & \\
\hline 1 & 1.14 & $(1.10-1.19)$ & 1.08 & $(1.01-1.15)$ & 1.04 & $(0.97-1.12)$ & 1.14 & $(0.92-1.41)$ & 1.25 & $(1.17-1.33)$ & 1.39 & $(1.23-1.58)$ \\
\hline 2 & 1.24 & $(1.14-1.36)$ & 1.17 & $(1.01-1.35)$ & 1.13 & $(0.97-1.32)$ & 1.92 & $(1.32-2.77)$ & 1.40 & $(1.22-1.60)$ & 1.49 & $(1.14-1.94)$ \\
\hline$\geq 3$ & 1.57 & $(1.38-1.80)$ & 1.60 & (1.29-1.98) & 1.12 & $(0.86-1.45)$ & 2.32 & $(1.33-4.03)$ & 1.85 & $(1.52-2.26)$ & 1.91 & $(1.28-2.83)$ \\
\hline \multicolumn{13}{|l|}{ ACB } \\
\hline 0 (reference) & 1.00 & & 1.00 & & 1.00 & & 1.00 & & 1.00 & & 1.00 & \\
\hline 1 & 1.12 & $(1.08-1.15)$ & 1.03 & $(0.98-1.09)$ & 1.18 & $(1.11-1.25)$ & 1.05 & $(0.86-1.26)$ & 1.12 & $(1.06-1.19)$ & 1.16 & $(1.04-1.30)$ \\
\hline 2 & 1.25 & $(1.19-1.32)$ & 1.10 & $(1.01-1.20)$ & 1.28 & $(1.16-1.40)$ & 1.57 & $(1.21-2.04)$ & 1.32 & $(1.21-1.43)$ & 1.36 & $(1.15-1.62)$ \\
\hline$\geq 3$ & 1.40 & $(1.32-1.49)$ & 1.21 & $(1.09-1.34)$ & 1.36 & $(1.23-1.51)$ & 2.22 & $(1.69-2.90)$ & 1.61 & $(1.46-1.77)$ & 1.71 & $(1.43-2.06)$ \\
\hline \multicolumn{13}{|l|}{ ADS } \\
\hline 0 (reference) & 1.00 & & 1.00 & & 1.00 & & 1.00 & & 1.00 & & 1.00 & \\
\hline 1 & 1.25 & $(1.21-1.30)$ & 1.15 & $(1.09-1.22)$ & 1.23 & $(1.16-1.31)$ & 1.39 & $(1.15-1.68)$ & 1.35 & $(1.27-1.43)$ & 1.35 & $(1.20-1.51)$ \\
\hline 2 & 1.35 & $(1.28-1.43)$ & 1.26 & $(1.16-1.38)$ & 1.27 & $(1.16-1.39)$ & 1.56 & $(1.19-2.05)$ & 1.54 & $(1.42-1.68)$ & 1.45 & $(1.22-1.72)$ \\
\hline$\geq 3$ & 1.61 & $(1.52-1.72)$ & 1.41 & $(1.27-1.57)$ & 1.49 & $(1.34-1.67)$ & 2.55 & $(1.91-3.40)$ & 1.88 & $(1.70-2.08)$ & 1.91 & $(1.57-2.32)$ \\
\hline
\end{tabular}

$E D$ emergency department, $a O R$ adjusted odds ratio, $C$ confidence interval, $K A B S$ Korean Anticholinergic Burden Scale, $A R S$ Anticholinergic Risk Scale, $A C B$ Anticholinergic Cognitive Burden scale, ADS Anticholinergic Drug Scale

${ }^{a}$ Co-morbid conditions, polypharmacy, excessive polypharmacy, exposure to sedative drugs, warfarin, insulin and digoxin, and more than 1 increase compared to previous month's anticholinergic burden were adjusted for the multivariate regression models 
retention (aOR: $2.16,95 \%$ CI: $1.81-2.58$ ) than those with a KABS score of 0 . High anticholinergic burden measured with the KABS showed the strongest association with delirium and urinary retention, as well as overall anticholinergic ED visits, among those measured with the four scales.

Table 4 shows the top 20 anticholinergic drugs that contributed to the average daily anticholinergic burden score measured by each four scales in the study population. Three of the scales identified the most frequently prescribed medication was ranitidine, followed by dimenhydrinate or chlorpheniramine. The ACB scale, however, found that hydrochlorothiazide contributed the most to the anticholinergic burden (15.7\%), which was not found in other scales. Among the anticholinergic drugs indexed solely in the KABS list, octylonium and trimebutine ranked 11th (2.6\%) and 13th (2.3\%), respectively.

\section{Discussion}

This study revealed that the anticholinergic burden, when measured with the KABS, identified a higher proportion of high anticholinergic burden as well as a stronger dose-response relationship for overall anticholinergic ED visits and individual anticholinergic adverse effect (delirium and urinary retention) than the three popular anticholinergic scales in older Korean adults.

Similar to the findings from other countries, such as New Zealand [23], Australia [16] and Germany [14], this current study confirmed that different scales identified different proportions of patients with a high anticholinergic burden. The ACB identified the largest proportion of exposure to anticholinergics (58.0\%), the ARS captured the least (37.6\%), and the KABS captured the largest proportion of older adults with a high anticholinergic burden (5.0\%). Despite the similar definition of anticholinergic exposure, prevalent anticholinergic drugs were different in the New Zealand study [23]. Gastrointestinal drugs such as ranitidine, cimetidine, and trimebutine ranked high in the list that contributed to the average daily $\mathrm{AB}$ scores in Korea, while antidepressant drugs such as nortriptyline, fluoxetine, and paroxetine ranked high in New Zealand. In Korea, first-generation antihistamines such as dimenhydrinate and chlorpheniramine ranked high in contributing to the anticholinergic burden, but in New Zealand, second-generation antihistamines, such as cetirizine and loratadine were presented as the most commonly prescribed drug.

Our study found the associations between anticholinergic burden and ED visits are in line with those from

Table 4 The top 20 drugs contributing to anticholinergic burden measured by each scale

\begin{tabular}{|c|c|c|c|c|c|c|c|c|c|c|c|}
\hline \multicolumn{3}{|l|}{ KABS } & \multicolumn{3}{|l|}{ ARS } & \multicolumn{3}{|l|}{ ACB } & \multicolumn{3}{|l|}{ ADS } \\
\hline Score & Drug & $\%$ & Score & Drug & $\%$ & Score & Drug & $\%$ & Score & Drug & $\%$ \\
\hline 1 & ranitidine ${ }^{a}$ & 11.4 & 1 & ranitidine $^{a}$ & 29.8 & 1 & hydrochlorothiazide & 15.7 & 2 & ranitidine $^{a}$ & 24.3 \\
\hline 3 & dimenhydrinate & 8.0 & 3 & chlorpheniramine ${ }^{a}$ & 18.8 & 1 & ranitidine ${ }^{a}$ & 10.3 & 3 & dimenhydrinate & 8.6 \\
\hline 3 & chlorpheniramine $e^{a}$ & 7.2 & 2 & cimetidine $^{a}$ & 12.8 & 3 & dimenhydrinate & 7.2 & 3 & chlorpheniramine ${ }^{a}$ & 7.7 \\
\hline 2 & tramadol & 6.7 & 3 & amitriptyline $^{a}$ & 4.7 & 3 & chlorpheniramine ${ }^{a}$ & 6.5 & 2 & cimetidine $^{a}$ & 5.2 \\
\hline 3 & solifenacin & 6.4 & 2 & cetirizine & 4.5 & 3 & solifenacin & 5.7 & 1 & furosemide & 5.0 \\
\hline 2 & cimetidine $^{a}$ & 4.9 & 1 & levodopa & 4.3 & 1 & furosemide & 4.2 & 1 & isosorbide & 4.3 \\
\hline 1 & furosemide & 4.7 & 2 & tolterodine $\mathrm{a}^{\mathrm{a}}$ & 3.9 & 1 & isosorbide & 3.6 & 1 & tramadol & 3.6 \\
\hline 3 & propiverine & 3.5 & 3 & hydroxyzine $e^{a}$ & 2.6 & 3 & propiverine & 3.1 & 1 & nifedipine & 3.3 \\
\hline 1 & escitalopram & 3.2 & 2 & amantadine $^{a}$ & 1.7 & 1 & escitalopram & 2.8 & 1 & alprazolam & 3.2 \\
\hline 1 & alprazolam & 3.0 & 1 & paroxetine $^{a}$ & 1.6 & 1 & nifedipine & 2.8 & 3 & tolterodine ${ }^{a}$ & 2.4 \\
\hline 3 & octylonium $^{\text {b }}$ & 2.6 & 3 & butylscopolamine ${ }^{a}$ & 1.4 & 1 & alprazolam & 2.7 & 1 & diltiazem & 2.3 \\
\hline 1 & levocetirizine & 2.5 & 2 & loratadine & 1.2 & 1 & atenolol & 2.4 & 1 & famotidine & 2.0 \\
\hline 1 & trimebutine $^{\mathrm{b}}$ & 2.3 & 2 & nortriptyline ${ }^{a}$ & 1.2 & 1 & levocetirizine & 2.3 & 1 & nizatidine & 1.9 \\
\hline 3 & tolterodine $^{\mathrm{a}}$ & 2.3 & 1 & mirtazapine & 1.2 & 1 & cimetidine $^{a}$ & 2.2 & 3 & amitriptyline $^{a}$ & 1.9 \\
\hline 3 & fesoterodine & 2.0 & 3 & imipramine $^{a}$ & 1.2 & 3 & tolterodine $e^{a}$ & 2.0 & 1 & prednisolone & 1.9 \\
\hline 3 & amitriptyline $^{a}$ & 1.8 & 1 & quetiapine $^{a}$ & 1.1 & 1 & doxazosin & 1.8 & 1 & methylprednisolone & 1.8 \\
\hline 1 & prednisolone & 1.8 & 2 & baclofen & 0.9 & 3 & fesoterodine & 1.8 & 1 & diazepam & 1.8 \\
\hline 1 & diazepam & 1.6 & 2 & loperamide ${ }^{a}$ & 0.9 & 3 & paroxetine $^{a}$ & 1.7 & 1 & digoxin & 1.6 \\
\hline 1 & digoxin & 1.5 & 1 & trazodone & 0.9 & 3 & amitriptyline $^{a}$ & 1.6 & 1 & dexamethasone & 1.3 \\
\hline 2 & paroxetine $^{a}$ & 1.2 & 2 & olanzapine $e^{a}$ & 0.8 & 1 & prednisolone & 1.6 & 1 & lorazepam & 1.3 \\
\hline
\end{tabular}

KABS Korean Anticholinergic Burden Scale, ARS Anticholinergic Risk Scale, ACB Anticholinergic Cognitive Burden, ADS Anticholinergic Drug Scale

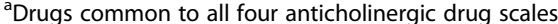

${ }^{b}$ Drugs included only in the KABS list 
previous studies, but our results of the comparative analyses among scales are different from earlier results. In a comparative study by Hsu et al., the ACB had the highest dose-dependent correlation with all-cause ED visits [15]. In contrast, our study showed that the ACB had the lowest correlation with ED visits due to anticholinergic adverse events. This discrepancy could be explained by the differences in prescribing practices as well as the availability of the various medications in the different countries. Mayer et al. reviewed published studies that evaluated the association of anticholinergic burden measured using different scales with patient reported outcomes, and found the results differed considerably depending on which scale was used [14]. Those findings implicated that the choice of anticholinergic burden assessment tools is an important issue in clinical applications, as the predictive validity for negative clinical outcomes may depend on the tool applied $[10,11,14,16,24,25]$.

To the best of our knowledge, this study is the first to show that a country-specific anticholinergic burden scale was superior in identifying patients with a high anticholinergic burden as having a higher association with acute anticholinergic adverse effects to the other scales developed in different countries. In addition, this study supplemented evidence that anticholinergic burden was associated with severe urinary retention and constipation leading to ED visits, whereas most previous studies focused on central nervous system effects, such as cognitive impairment and dementia, or falls [26, 27].

There are several limitations to be considered. First, similar to previous studies, there are inherent limitations of claims data analyses such as over-the-counter medications may not be included, cannot validate whether medications are actually taken, and the inability to take into account laboratory findings such as kidney or liver function [20]. Second, as we selected control using propensity score matching with minimum matching variables, selection bias due to residual confounding inherent in case-control study might affect the study results even though we included unbalanced variables in regression for adjustment. Finally, this study validated the KABS focusing on anticholinergic adverse effects that may occur with short-term use in older adults. Validation of the KABS regarding the prediction of longer-term negative clinical outcomes of anticholinergic burden, such as cognitive impairment and dementia, should be conducted.

\section{Conclusion}

In conclusion, this study demonstrated that the country-specific anticholinergic burden scale, KABS, is superior to previously developed scales for identifying patients with high anticholinergic burden as having high association with ED visits secondary to anticholinergic adverse events in older Korean adults. The KABS might be a practical scale for assessing anticholinergic burden and subsequently deprescribing inappropriate medications to prevent anticholinergic complications.

\section{Supplementary Information}

The online version contains supplementary material available at https://doi. org/10.1186/s40360-020-00467-6.

Additional file 1. Diagnostic codes used to identify anticholinergic adverse outcomes and comorbidities.

Additional file 2. The comparable list of anticholinergics in four scales.

\section{Abbreviations}

KABS: Korean Anticholinergic Burden Scale; AB: Anticholinergic Burden; ED: Emergency Department; ARS: Anticholinergic Risk Scale;

ACB: Anticholinergic Cognitive Burden Scale; ADS: Anticholinergic Drug Scale; HIRA: Health Insurance Review and Assessment Service; APS: Adult Patient Sample; DDD: Defined Daily Dose; WHO: World Health Organization; CCl: Charlson Comorbidity Index; aOR: adjusted Odds Ratio; Cl: Confidence Interval

\section{Acknowledgements}

Not applicable.

\section{Authors' contributions}

Each author has made substantial contributions according to the recommendations by The International Committee of Medical Journal Editors (ICMJE). SH, JE contributed to conception, acquisition, analysis, and preparation of manuscript for this study. $\mathrm{KH}, \mathrm{YM}$ and $\mathrm{Kl}$ contributed to analysis, interpretation. JY contributed to the design and implementation of the research, to the analysis of the results and to the writing of the manuscript. All authors revised the manuscript critically and have read and approved the final manuscript.

\section{Funding}

This research was supported by the Basic Science Research Program through the National Research Foundation of Korea funded by the Ministry of Education (2017R1D1A1B03029528).

\section{Availability of data and materials}

The data that support the findings of this study are available from Health Insurance Review and Assessment Service (HIRA) but restrictions apply to the availability of these data, which were used under license for the current study, and so are not publicly available. Data are however available from the authors upon reasonable request and with permission of HIRA.

\section{Ethics approval and consent to participate}

This study obtained an ethical approval from the Institutional Review Board of Hanyang University (No. HYl-17-007-1). Informed consent was waived because we used encrypted claims data.

\section{Consent for publication}

Not applicable.

\section{Competing interests}

The authors declare that they have no competing interests.

\section{Author details}

${ }^{1}$ College of Pharmacy and Institute of Pharmaceutical Science and Technology, Hanyang University, Ansan, Gyeonggi-do, Republic of Korea. ${ }^{2}$ College of Pharmacy and Research Institute of Pharmaceutical Sciences, Seoul National University, Seoul, Republic of Korea. ${ }^{3}$ College of Pharmacy, Yeungnam University, Gyeongsan-si, Gyeongsangbuk-do, Republic of Korea. ${ }^{4}$ Department of Internal Medicine, Seoul National University Bundang Hospital, Seognam-si, Gyeonggi-do, Republic of Korea. 
Received: 4 August 2020 Accepted: 14 December 2020

Published online: 07 January 2021

\section{References}

1. By the American Geriatrics Society Beers Criteria Update Expert P. American Geriatrics Society 2015 updated beers criteria for potentially inappropriate medication use in older adults. J Am Geriatr Soc. 2015;63(11):2227-46. https://doi.org/10.1111/jgs.13702.

2. Tune LE. Anticholinergic effects of medication in elderly patients. J Clin Psychiatry. 2001;62(Suppl 21):11-4.

3. Olsson J, Bergman A, Carlsten A, Oke T, Bernsten C, Schmidt IK, et al. Quality of drug prescribing in elderly people in nursing homes and special care units for dementia: a cross-sectional computerized pharmacy register analysis. Clin Drug Investig. 2010;30(5):289-300. https://doi.org/10.2165/ 11534320-000000000-00000.

4. Tay HS, Soiza RL, Mangoni AA. Minimizing anticholinergic drug prescribing in older hospitalized patients: a full audit cycle. Ther Adv Drug Saf. 2014;5(3): 121-8. https://doi.org/10.1177/2042098614523638.

5. Ailabouni N, Mangin D, Nishtala PS. DEFEAT-polypharmacy: deprescribing anticholinergic and sedative medicines feasibility trial in residential aged care facilities. Int J Clin Pharm. 2019;41(1):167-78. https://doi.org/10.1007/ s11096-019-00784-9.

6. Rudolph JL, Salow MJ, Angelini MC, MCGlinchey RE. The anticholinergic risk scale and anticholinergic adverse effects in older persons. Arch Intern Med. 2008;168(5):508-13. https://doi.org/10.1001/archinternmed.2007.106.

7. Boustani M, Campbell N, Munger S, Maidment I, Fox C. Impact of anticholinergics on the aging brain: a review and practical application; 2008

8. Carnahan RM, Lund BC, Perry PJ, Pollock BG, Culp KR. The anticholinergic drug scale as a measure of drug-related anticholinergic burden: associations with serum anticholinergic activity. J Clin Pharmacol. 2006;46(12):1481-6. https://doi.org/10.1177/0091270006292126.

9. Villalba-Moreno AM, Alfaro-Lara ER, Perez-Guerrero MC, Nieto-Martin MD, Santos-Ramos B. Systematic review on the use of anticholinergic scales in poly pathological patients. Arch Gerontol Geriatr. 2016;62:1-8. https://doi. org/10.1016/j.archger.2015.10.002

10. Mayer T, Haefeli WE, Seidling HM. Different methods, different results--how do available methods link a patient's anticholinergic load with adverse outcomes? Eur J Clin Pharmacol. 2015;71(11):1299-314. https://doi.org/10. 1007/s00228-015-1932-x

11. Lertxundi U, Domingo-Echaburu S, Hernandez R, Peral J, Medrano J. Expertbased drug lists to measure anticholinergic burden: similar names, different results. Psychogeriatrics. 2013;13(1):17-24. https://doi.org/10.1111/j.14798301.2012.00418.x

12. Salahudeen MS, Duffull SB, Nishtala PS. Anticholinergic burden quantified by anticholinergic risk scales and adverse outcomes in older people: a systematic review. BMC Geriatr. 2015;15:31. https://doi.org/10.1186/s12877015-0029-9

13. Jun $K$, Hwang S, Ah YM, Suh Y, Lee JY. Development of an anticholinergic burden scale specific for Korean older adults. Geriatr Gerontol Int. 2019; 19(7):628-34. https://doi.org/10.1111/ggi.13680.

14. Mayer T, Meid AD, Saum KU, Brenner H, Schottker B, Seidling HM, et al. Comparison of nine instruments to calculate anticholinergic load in a large cohort of older outpatients: association with cognitive and functional decline, falls, and use of laxatives. Am J Geriatr Psychiatry. 2017:25(5):531-40. https://doi.org/10.1016/j.jagp.2017.01.009.

15. Hsu WH, Wen YW, Chen LK, Hsiao FY. Comparative associations between measures of anti-cholinergic burden and adverse clinical outcomes. Ann Fam Med. 2017;15(6):561-9. https://doi.org/10.1370/afm.2131.

16. Pont LG, Nielen JT, McLachlan AJ, Gnjidic D, Chan L, Cumming RG, et al. Measuring anticholinergic drug exposure in older community-dwelling Australian men: a comparison of four different measures. Br J Clin Pharmacol. 2015;80(5):1169-75. https://doi.org/10.1111/bcp.12670

17. Caldwell N, Srebotnjak T, Wang T, Hsia R. "How much will I get charged for this?" Patient charges for top ten diagnoses in the emergency department. PLoS One. 2013;8(2):e55491. https://doi.org/10.1371/journal.pone.0055491.

18. Kim L, Kim JA, Kim S. A guide for the utilization of Health Insurance Review and Assessment Service national patient samples. Epidemiol Health. 2014; 36:e2014008. https://doi.org/10.4178/epih/e2014008.

19. WHO. ATC/DDD Index 2020. 2020. https://www.whocc.no/atc_ddd_index/. Accessed 10 Jul 2020.
20. Hwang S, Jun K, Ah YM, Han E, Chung JE, Lee JY. Impact of anticholinergic burden on emergency department visits among older adults in Korea: a national population cohort study. Arch Gerontol Geriatr. 2019;85:103912. https://doi.org/10.1016/j.archger.2019.103912.

21. Leipzig RM, Cumming RG, Tinetti ME. Drugs and falls in older people: a systematic review and meta-analysis: I. Psychotropic drugs. J Am Geriatr Soc. 1999;47(1):30-9.

22. Linjakumpu T, Hartikainen S, Klaukka T, Koponen H, Kivela SL, Isoaho R. A model to classify the sedative load of drugs. Int J Geriatr Psychiatry. 2003: 18(6):542-4. https://doi.org/10.1002/gps.846

23. Salahudeen MS, Hilmer SN, Nishtala PS. Comparison of anticholinergic risk scales and associations with adverse health outcomes in older people. J Am Geriatr Soc. 2015;63(1):85-90. https://doi.org/10.1111/jgs.13206.

24. Pasina L, Djade CD, Lucca U, Nobili A, Tettamanti M, Franchi C, et al. Association of anticholinergic burden with cognitive and functional status in a cohort of hospitalized elderly: comparison of the anticholinergic cognitive burden scale and anticholinergic risk scale: results from the REPOSI study. Drugs Aging. 2013;30(2):103-12. https://doi.org/10.1007/ s40266-012-0044-x.

25. Nishtala PS, Salahudeen MS, Hilmer SN. Anticholinergics: theoretical and clinical overview. Expert Opin Drug Saf. 2016;15(6):753-68. https://doi.org/ 10.1517/14740338.2016.1165664.

26. Fox C, Smith T, Maidment I, Chan WY, Bua N, Myint PK, et al. Effect of medications with anti-cholinergic properties on cognitive function, delirium, physical function and mortality: a systematic review. Age Ageing. 2014;43(5): 604-15. https://doi.org/10.1093/ageing/afu096.

27. Landi F, Dell'Aquila G, Collamati A, Martone AM, Zuliani G, Gasperini B, et al. Anticholinergic drug use and negative outcomes among the frail elderly population living in a nursing home. J Am Med Dir Assoc. 2014;15(11):8259. https://doi.org/10.1016/j.jamda.2014.08.002.

\section{Publisher's Note}

Springer Nature remains neutral with regard to jurisdictional claims in published maps and institutional affiliations.
Ready to submit your research? Choose BMC and benefit from:

- fast, convenient online submission

- thorough peer review by experienced researchers in your field

- rapid publication on acceptance

- support for research data, including large and complex data types

- gold Open Access which fosters wider collaboration and increased citations

- maximum visibility for your research: over $100 \mathrm{M}$ website views per year

At BMC, research is always in progress.

Learn more biomedcentral.com/submission 